\title{
To flee, or not to flee, that is the question for older asylum seekers
}

As psychiatrists, we assess, diagnose, and manage psychiatric problems in older adults. We also have an important role as their advocates and in promoting positive attitudes toward this group. Only in the 1950s was there increasing recognition that older age did not necessarily equate to senility, that treatment of psychiatric disorders in this group was possible, and could have good outcomes (Roth, 1955). There is, however, still an undercurrent of pervasive negative attitudes toward the elderly, and their psychiatric needs continue to be marginalized, with less attention from the media, funding bodies, and even from our medical and surgical colleagues (Penson et al., 2004).

Our knowledge of older asylum seekers is an illustration of this situation. The majority of the literature and media coverage focuses on adults and children with little to no consideration of issues relating to the elderly asylum seeker. Even allowing for the smaller number of older asylum seekersin Australia, 394 people older than 60 years (1.5\%) lodged a protection claim in 2012-2013 (compared to $16 \%$, which is the number of claims lodged by people under 18 years) (Department of Immigration and Border Protection, 2013) - there is a dearth of studies investigating their mental health.

An asylum seeker is defined as any person who has fled their own country and is seeking international protection as a refugee, whose claim has not yet been determined. Under the United Nations Refugee Convention (1951) and its Protocol (1967), a person is owed protection, and recognized as a refugee, if they are outside their country (in contrast to an internally displaced person) and are unable or unwilling to return due to a well-founded fear that they will be persecuted because of their race, religion, nationality, political opinion, or membership of a particular social group. As of April 2011, 147 member states of the United Nations are signatories to either the convention or protocol. They are obligated to allow people fleeing persecution to seek asylum, and have their refugee claims processed.

The vexing issue of asylum seekers and refugees has been a longstanding social and political issue thrown into sharp relief by recent developments in
North Africa and Syria. Ongoing war, conflict, and religious persecution in Syria, the Congo, South Sudan, Central African Republic and Mali, have forced more than 1.5 million individuals to leave their country recently and seek asylum elsewhere. In addition, at least 456,000 people applied for asylum in over 170 countries in the first half of 2013 (United Nations High Commissioner for Refugees, 2013b).

Although countries may be signatories to the convention and protocol, each country has their own interpretation of their obligations, which often depends on the country's immigration and political system. As can be seen in Tables 1 and 2, a disproportionate burden of caring for asylum seekers falls on the world's poorest countries, while the leading industrialized asylum resettlement nations, the United States, Germany, France, Sweden, and the United Kingdom, only accepted 190,700 new applications in 2012 (United Nations High Commissioner for Refugees, 2012). In contrast, this year saw Lebanon accept its 1 millionth refugee from Syria, and this is anticipated to reach 1.5 million by year's end (United Nations High Commissioner for Refugees, 2013a).

While there are established reports of high rates of mental illness, such as posttraumatic stress disorder (PTSD), depressive and anxiety disorders, and other psychiatric symptomatology in adult asylum seekers compared to the general community (Burnett and Peel, 2001), we have little information about older asylum seekers in terms of epidemiology and prevalence of mental illness. Moreover, we know relatively little about the mental health consequences for asylum seekers as they age. One follow up study of 483 Cambodian refugees settled in the United States (with a mean follow up age of 52 years) found there were still high rates of PTSD $(62 \%)$ and major depression $(51 \%)$ in this group after two decades. Bivariate analyses demonstrated that older age, being retired or disabled and being under employed were also associated with higher rates of these mental disorders (Marshall et al., 2005).

A combination of: premigration trauma, such as religious persecution, racial discrimination, war, and other conflict; migration trauma, such 
Table 1. Top 10 major refugee-hosting countries, end of 2012 (adapted from UNHCR Global Trends 2012)

\begin{tabular}{ll}
\hline COUNTRY & $\begin{array}{l}\text { NUMBER (APPROXIMATELY } \\
\text { ONLY, IN MILLIONS) }\end{array}$ \\
Pakistan & 1.600 \\
Iran & 0.870 \\
Jordan & 0.589 \\
Lebanon & 0.565 \\
Kenya & 0.476 \\
Turkey & 0.376 \\
Chad & 0.373 \\
Ethiopia & 0.302 \\
China & 0.301 \\
United States & 0.260 \\
\hline
\end{tabular}

Table 2. Top 10 rankings of countries who accept number of refugees per 1,000 inhabitants, 2012 (adapted from UNHCR Global Trends 2012)

\begin{tabular}{ll}
\hline COUNTRY & $\begin{array}{l}\text { NUMBER PER 1000 } \\
\text { INHABITANTS }\end{array}$ \\
\hline Jordan & 49 \\
Chad & 33 \\
Lebanon & 32 \\
Republic of Congo & 24 \\
Syrian Arab Republic & 23 \\
Mauritania & 23 \\
Dijbouti & 22 \\
Malta & 20 \\
South Sudan & 20 \\
Montenegro & 18 \\
\hline
\end{tabular}

as hazardous boat trips and experiences in refugee camps; and postmigration living difficulties, including the protracted process of refugee status determination, detention, lack of language skills, and poor access to services, all contribute to psychiatric symptoms experienced by asylum seekers. Being held in immigration detention centres (IDCs), potentially exposes asylum seekers to poor living conditions, the deprivation of liberty, mistreatment by officers, and being involved or witnessing other traumas such as riots, hunger strikes, and self-harm, which can contribute to adverse mental health consequences (Silove et al., 2001; Steel and Silove, 2001; Sultan and O'sullivan, 2001; Mares et al., 2002; Steel et al., 2004). In some countries, processing of visa applications occurs offshore, where centres may be less appropriate for housing large numbers of people, including those of an older age. Lack of nutritious food and physical activity may lead to exacerbation of physical problems. There may also be insufficient access to medical care for ongoing management of chronic medical problems such as diabetes and hypertension, but also disorders related to overcrowding and poor hygiene such as infections, and tropical diseases including dengue fever and malaria (Sultan and O'sullivan, 2001; Phillips, 2010; Green and Eagar, 2010).

There is less documented about the mental health of asylum seekers living in the community, but postmigration stressors such as discrimination, lack of access to health services and housing, financial stressors, lack of employment/work rights, social isolation, and concern for family left behind may also contribute to the persistence of poor mental health in this group (Lindencrona et al., 2008). A prolonged or problematic refugee determination process (RDP) may be a significant postmigration stressor with studies demonstrating lower levels of depression and PTSD, and improved quality of life, in asylum seekers whose claims have been processed more rapidly (Ryan et al., 2008; Steel et al., 1999).

Asylum seeker status may limit access to important services relevant to older age, such as obtaining financial assistance (ie. the age pension), free healthcare, and appropriate accommodation, including entry in to residential care. They may not be able to access general practitioners and specialist services easily, or obtain aides such as glasses, dentures, walking frames, and hearing devices (Norredam et al., 2006; Spike et al., 2011). In addition, although many older people do not work, asylum seekers of older age who might choose employment or voluntary work, may be not permitted to do so.

There are other critical issues which are relevant to older age. From our clinical experience and research in victims of abuse, aging war veterans and Holocaust survivors, we have some notion of how aging can uniquely impact on the mental health of older people. Advancing age may represent a differential vulnerability factor which moderates the impact of exposure to a stressor (Averill and Beck, 2000), and it has been suggested that older adults are more vulnerable to stressors, as they may have less coping skills, physical and cognitive deterioration, and less social and financial support. The effects of trauma in older people may also be different to those experienced by younger people. Preoccupation with the trauma, avoidance, sleep disturbance, intrusive thoughts, and crying may be more frequent, compared to younger and middle aged adults (Hagstrom, 1995).

Cognitive impairment and dementia can worsen PTSD symptoms, because the mechanisms and strategies which keep traumatic memories under control may weaken, resulting in a reactivation of these memories. Flashbacks may also recur. These 
may result in associated depressive and anxiety symptoms (Grossman et al., 2004).

Furthermore, cultural norms of help-seeking behaviour and different expressions of symptoms (Bhugra and Becker, 2005), poor mental health literacy, stoicism, and lack of knowledge of where to obtain appropriate treatment (Gilgen et al., 2005), all could contribute to potentially adverse mental health outcomes in older asylum seekers.

Nonetheless, past research suggests that older people may cope better owing to "psychological immunization" by earlier life events (Henderson, 1994). They can be remarkably resilient and may manage stress comparatively well, as their life experience can help them adjust with difficulties and negative events in later life (Bell, 1978). Being more positive and accepting of oneself, displaying optimism, and having strong social networks have all been found to contribute to "successful ageing" (Anstey and Luszcz, 2002). Resilience may involve both individual factors such as positive temperament, beliefs in internal control, self-efficacy, and social resources such as family cohesion and supportive communities (Ayalon, 2005)

With changing immigration policies, and the real potential for asylum seekers to remain in detention, or in the community, for prolonged periods of time, there may be a growing number of older asylum seekers in many countries. We need to consider the mental health ramifications of this situation, as there is a lack of definitive research in this area. Improved access to basic needs, such as housing, nutrition, financial assistance, and healthcare, could assist in alleviating the adverse effects. This area needs to be explored, in order to get a better understanding of these issues, to inform recommendations and interventions. This will allow us to advocate better for this marginalized group of people, and influence social and public policy for positive change.

We must not forget the example of Dr Sigmund Freud. We know him as the father of psychoanalysis, a giant in 20th century thought, and a family man. $\mathrm{He}$ was also an older asylum seeker. $\mathrm{He}$ was 82 years old when forced to flee Vienna with his family, when Austria was annexed by the Nazis in 1938. Due to his Jewish religion and being the founder of psychoanalysis, Dr Freud had been subject to interrogation and threats by the Gestapo, and had many of his books burnt and substantial sums of money extorted. Because of his renown and personal connections, he was fortunate enough to be able to secure a safe passage to London, but left behind four sisters who died in concentration camps. Even though his journey to London was relatively smooth, he had family and other supports, he was able to communicate in English, and he managed to continue to work, we know from his writings that despite these advantages, Dr Freud had health problems and ongoing challenges with adjusting to life in his new home. Being forced to flee one's country of origin can happen to anyone, at any age, and at anytime. Most asylum seekers do not have such connections, are more impoverished and potentially are at much higher risk of adverse outcomes.

\section{Conflict of interest}

None

\section{SAMANTHA LOI ${ }^{1}$ AND SURESH SUNDRAM ${ }^{2}$}

${ }^{1}$ Academic Unit for Psychiatry of Old Age, University of Melbourne, St Vincent's Health, St George's Hospital;

North Western Aged Mental Health, Melbourne

Health, Parkville, Victoria, Australia

${ }^{2}$ Florey Institute of Neuroscience and Mental Health, Kenneth Myer BuildingParkville; Northern Psychiatry Research Centre, The Northern Hospital, Epping, Victoria, Australia

Email: Samantha.loi2@svhm.org.au

\section{References}

Anstey, K. J. and Luszcz, M. A. (2002). Psychosocial factors, gender and late-life mortality. Ageing International, 27, 73-89.

Averill, P. M. and Beck, J. G. (2000). Posttraumatic stress disorder in older adults: a conceptual review. Fournal of Anxiety Disorders, 14, 133-156.

Ayalon, L. (2005). Challenges associated with the study of resilience to trauma in Holocaust survivors. Fournal of Loss and Trauma, 10, 347-358.

Bell, B. D. (1978). Disaster impact and response: overcoming the thousand natural shocks. Gerontologist, 18, 531-540.

Bhugra, D. and Becker, M. A. (2005). Migration, cultural bereavement and cultural identity. World Psychiatry, 4, 18-24.

Burnett, A. and Peel, M. (2001). Health needs of asylum seekers and refugees. British Medical fournal, 322, 544-547.

Department of Immigration and Border Protection. (2013). Asylum trends-Australia. Available at: http://www.immi.gov.au/media/publications/statistics/ immigration-update/asylum-trends-aus-2012-13.pdf; Accessed 1 May 2014.

Gilgen, D. et al. (2005). Impact of migration on illness experience and help-seeking strategies of patients from Turkey and Bosnia in primary health care in Basel. Health Place, 11, 261-273.

Green, J. P. and Eagar, K. (2010). The health of people in Australian immigration detention centres. Medical fournal of Australia, 192, 65-70.

Grossman, A. B., Levin, B. E., Katzen, H. L. and Lechner, S. (2004). PTSD symptoms and onset of 
neurologic disease in elderly trauma survivors. Fournal of Clinical and Experimental Neuropsychology, 26, 698705.

Hagstrom, R. (1995). The acute psychological impact on survivors following a train accident. Fournal of Traumatic Stress, 8, 391-402.

Henderson, A. S. (1994). Does ageing protect against depression? Social Psychiatry and Psychiatric Epidemiology, 29, 107-109.

Lindencrona, F., Ekblad, S. and Hauff, E. (2008). Mental health of recently resettled refugees from the Middle East in Sweden: the impact of pre-settlement trauma, resettlement stress and capacity to handle stress. Social Psychiatry Psychiatric Epidemiology, 43, 121-131.

Mares, S., Newman, L., Dudley, M. and Gale, F. (2002). Seeking refuge, losing hope: parents and children in immigration detention. Australasian Psychiatry, 10, 9196.

Marshall, G. N., Schell, T. L., Elliott, M. N., Berthold, S. M. and Chun, C. A. (2005). Mental health of Cambodian refugees 2 decades after resettlement in the United States. Fournal of the American Medical Association, 294, 571-579.

Norredam, M., Mygind, A. and Krasnik, A. (2006). Access to health care for asylum seekers in the European Union-a comparative study of country policies. European Fournal of Public Health, 16, 286-290.

Penson, R. T., Daniels, K. J. and Lynch, T. J., Jr. (2004). Too old to care? Oncologist, 9, 343-352.

Phillips, C. B. 2010. Immigration detention and health. Medical fournal of Australia, 192, 61-62.

Roth, M. 1955. The natural history of mental disorder in old age. Fournal of Mental Science, 101, 281-301.

Ryan, D. A., Benson, C. A. and Dooley, B. A. (2008). Psychological distress and the asylum process. Fournal of Nervous Mental Disease, 196, 37-45.
Silove, D., Steel, Z. and Mollica, R. (2001). Detention of asylum seekers: assault on health, human rights and social development. The Lancet, 357, 1436-1437.

Spike, E. A., Smith, M. M. and Harris, M. F. (2011). Access to primary health care services by community-based asylum seekers. Medical fournal of Australia, 195, 188-191.

Steel, Z., Momartin, S., Bateman, C., Hafshejani, A. and Silove, D. (2004). Psychiatric status of asylum seeker families held for a protracted period in a remote detention centre in Australia. Australian and New Zealand fournal of Public Health, 28, 527-536.

Steel, Z. and Silove, D. (2001). The mental health implications of detaining asylum seekers. Medical fournal of Australia, 175, 596-599.

Steel, Z., Silove, D., Bird, K., Mcgorry, P. and Mohan, P. (1999). Pathways from war trauma to posttraumatic stress symptoms amongst Tamil asylum seekers, refugees and immigrants. Fournal of Traumatic Stress, 12, 421-435.

Sultan, A. and O'sullivan, K. (2001). Psychological disturbances in asylum seekers held in long term detention: a participant observer account. Medical Fournal of Australia, 175, 593-596.

United Nations High Commissioner for Refugees. (2012). UNHCR Global Trends 2012. Available at: http://www.unhcr.org/cgi-bin/texis/vtx/home/ opendocPDFViewer.html?docid=51bacb0f 9 \&query= refugees $\% 20$ accepted $\% 20$ by $\% 20$ GDP.

United Nations High Commissioner for Refugees. (2013a). 2014 Syria Regional Response Plan-Lebanon. Available at: http://www.unhcr.org/syriarrp6/docs/ syria-rrp6-lebanon-response-plan.pdf\#A); Accessed 30 April, 2014.

United Nations High Commissioner for Refugees. (2013b). UNHCR Mid-Year Trends 2013. Available at: http://unhcr.org.uk/fileadmin/user_upload/docs/ Mid_year_trends_2013.pdf; Accessed 6 March, 2014. 